\title{
Development and validation of the pick-up service quality scale of the buy-online-pick-up-in-store service
}

\author{
Yeonjoo Lee ${ }^{1,2} \cdot$ Sunmee Choi $^{2,3} \cdot$ Joy M. Field ${ }^{4}$ \\ Received: 9 January 2020 / Revised: 31 July 2020 / Accepted: 5 August 2020 / Published online: 15 August 2020 \\ (C) Springer Science+Business Media, LLC, part of Springer Nature 2020
}

\begin{abstract}
Buy-Online-Pick-up-in-Store (BOPS) service is a popular omnichannel retail initiative, intended to enhance the convenience of online customers. Focusing on the pick-up (PU) stage of BOPS service, we develop a comprehensive scale (BOPS-PU-QUAL) for its quality perceived by customers. A multi-step scale development procedure involving one qualitative and two quantitative studies resulted in a scale consisting of 16 items under four dimensions. Service effectiveness is found to be the strongest influencer on quality perceptions of BOPS-PU, followed by problem-handling, ease of access, and item-quality. A structural equation analysis reveals that BOPS-PU-QUAL perceptions positively affect customers' behavioral intentions towards the brand's BOPS service, with the relationship fully mediated by satisfaction with BOPS. This study contributes to omnichannel service quality research by identifying the critical quality dimensions of BOPS pick-up service that reflect the uniqueness of BOPS customers. These findings help practitioners realize the importance of managing BOPS-PU service quality and provide practical guidance.
\end{abstract}

Keywords Buy-online-pick-up-in-store · Omnichannel retailing · Click-and-collect · Pick-up service · Scale development . Service quality

\section{Introduction}

Many retailers today offer multiple channels, or customer contact points or media through which the firm and its customers interact (Neslin et al. 2006), to allow customers to choose channels of their preference. These multichannel retailers are now evolving into omnichannel retailers by integrating and coordinating the channels (Levy et al. 2014). In the omnichannel retail context, firms offer diverse channels and

Joy M. Field

fieldjo@bc.edu

Yeonjoo Lee

yjlee@umn.edu

Sunmee Choi

sc128@yonsei.ac.kr

1 Carlson School of Management, University of Minnesota, Minneapolis, MN, USA

2 School of Business, Yonsei University, Seoul, Republic of Korea

3 College of Business and Management, VinUniversity, Hanoi, Vietnam

4 Carroll School of Management, Boston College, 350 Fulton Hall, 140 Commonwealth Avenue, Chestnut Hill, MA 02492, USA touchpoints, including online, offline, mobile, and Social Networking Service (SNS), that are integrated and managed under one brand strategy to provide customers with a seamless retail experience (Verhoef et al. 2015). Buy-Online-Pick-upin-Store (BOPS) service has emerged as an integral part of this omnichannel strategy. BOPS service, also known as "clickand-collect," allows consumers to purchase items online and pick them up at an offline store instead of having the items delivered. A large number of retailers in diverse industries such as groceries, clothing, and department stores have adopted BOPS as a major channel integration strategy. For example, as of 2017, Walmart was offering the grocery pick-up service in 1200 locations and announced plans to add the service to 1000 more sites (Hsu and Wingfield 2018).

BOPS is one of the most popular omnichannel services used by customers. According to a survey of 1058 U.S. consumers, $50 \%$ of respondents reported having used BOPS in the previous 12 months (JDA 2017). Retailers also ranked BOPS as one of their highest omnichannel strategic priorities (Forrester 2014). BOPS allows customers to avoid shipping fees, get items quickly without waiting for delivery, deal with errors immediately when picking up, and avoid the hassle of wandering around the store looking for items (Berman and Thelen 2004; Bell and Howell 2017). At the same time, 
retailers benefit from increased store traffic and cross-selling opportunities (Gao and Su 2016). Furthermore, BOPS fits the current retail climate with limited human interactions due to the COVID-19 pandemic. The number of BOPS orders significantly grew during the pandemic because BOPS is considered a safe shopping method (Adobe Analytics 2020).

In the BOPS shopping journey, the online shopping site and offline store are designed and function as distinct processes to meet particular customer wants and needs. Customers search, select, and purchase items online at the time and place of their choosing. Then, pick-up is done offline at a designated time and place through interactions with service providers. In other words, the two channels offer different experiences to customers. In practice, BOPS problems arise mostly in the offline pick-up process. Rosenmayer et al. (2018)'s analysis of customer feedback showed that "bricks-and-mortar" shopping problems are most prevalent (24\%) among omnichannel service failures, whereas "website design" issues account for only a small proportion (8\%). Customers can experience various service problems in the offline channel, where they physically and more intimately interact with the retailer. Common problems include long waiting times, staff being too slow or unable to find the order, lack of signs indicating the pick-up area, and no dedicated pick-up counter or staff (JDA 2017; Barr 2018).

Managing the pick-up service quality of BOPS is critical for omnichannel retailers. Consumers who utilize multiple channels are generally considered more valuable than singlechannel customers to retailers because they are more loyal and spend more (Venkatesan et al. 2007; Kushwaha and Shankar 2013; Sopadjieva et al. 2017). Song et al. (2020) found that BOPS usage generates significant additional economic value in both online and offline channels. Furthermore, the shopping experience during the physical encounter largely determines the customer-brand relationship due to its high level of intimacy (Bell et al. 2018). For example, in the service failure context, the impact of offline failures on customer satisfaction and post-purchase intention is stronger than online failures (Harris et al. 2006).

Understanding which aspects of the pick-up service are essential for BOPS service quality evaluation is the first step towards ensuring superior service quality. Developing valid and reliable measurement scales is a critical foundation for rigorous empirical research (Roth et al. 2008). Some scales for measuring service quality of multichannel and omnichannel retailers have been developed (Cassab and MacLachlan 2009; Wu and Chang 2016; Zhang et al. 2019), but they do not provide specific guidelines for evaluating the service quality of particular omnichannel services, such as BOPS, that are provided by these retailers. Distinct types of omnichannel services require different scales because the functions and shopping processes are unique for each service. For instance, while BOPS allows online customers to use the offline channel to pick up the item without shipping fees on the same day, in-store mobile applications enhance the customer's offline shopping experience with coupons and product information from the online channel.

The few existing studies on BOPS service quality dimensions have focused mostly on online service quality (Swaid and Wigand 2012) or logistics service quality (Murfield et al. 2017), with limited attention to the offline pick-up service. To the best of our knowledge, only one BOPS service quality study includes offline pick-up quality, but minimally in only one of its dimensions (Swaid and Wigand 2012). Moreover, existing research on retail service quality may not map directly to BOPS customers. For example, compared to conventional shoppers, BOPS customers tend to be more concerned with the convenience and speed of shopping (Jara et al. 2018).

Considering the vital influence of the offline store channel experience on BOPS service quality perceptions, limited scale development and managerial guidance for ensuring BOPS offline quality, and questionable applicability of related research on multichannel service, this study aims to fill the research gap by giving full consideration to BOPS pick-up quality and identifying the dimensions of the pick-up service influential on customer evaluation of BOPS service quality. The primary objectives of this research are to: (1) develop a comprehensive BOPS pick-up service quality scale - BOPS-PU$Q U A L$ - which focuses on customer perceptions of service quality during the offline pick-up service, (2) validate the scale, and (3) explore its theoretical relationships with customers' attitudinal responses.

The remainder of this article consists of three sections. First, we introduce relevant literature and provide the conceptual background of BOPS-PU-QUAL. Next, we describe the scale development process and present outcomes of validity tests. In the final section, we discuss the findings of the study and present implications and future research directions.

\section{Literature review}

\subsection{Comparison of BOPS customers and online customers}

BOPS customers search, select, and purchase on the retailer's website and then choose an alternate channel - offline store for product collection. However, Herhausen et al. (2015) found that online-offline multichannel users such as BOPS customers are actually online shoppers by nature. The results of their discrete channel choice analyses show that customers who buy from integrated online-offline stores would otherwise buy from online-only stores and not physical stores. In addition, multichannel customers share common characteristics with online customers. They both tend to be younger, more innovative, and better educated (Konuș et al. 2008; 
Kushwaha and Shankar 2013; Jara et al. 2018). Despite these similarities, BOPS customers choose to move from an online to an offline channel to complete their transactions, while online-only customers remain in the single channel. As a basis to compare and contrast these two types of customers, we first need to understand the choice of the online channel for at least part of the process.

To do this, we draw on insights from four literature streams: Technology Acceptance Model (TAM), customer efficiency, online retail, and Theory of Planned Behavior (TPB). According to TAM, two factors determine the behavioral intention and actual usage of an information technology system: perceived usefulness (for accomplishing what the user wants to do) and perceived ease of use (to minimize user effort) (Davis 1989; Venkatesh and Davis 2000). In addition, perceived usefulness is influenced by perceived ease of use (i.e., technologies that are easier to use are considered more useful). Relatedly, the concept of "customer efficiency," from the service operations management literature, suggests that online retailers can help customers to become more efficient (i.e., reduce time and effort to transact through an online channel) by creating a user-friendly, efficiency-focused website and process (Xue and Harker 2002; Field et al. 2012). This not only benefits the customer but also is associated with increased customer loyalty and service provider profitability (Xue et al. 2007). Online retailers have, in fact, focused on making their processes easy to use, efficient, and useful to customers. For example, as early as the 1990s, Amazon introduced one-click ordering to make the ordering process as frictionless as possible. As a result, "the online channel is characterized by its efficiency in terms of convenience, accessibility, and ease of use" (Cambra-Fierro et al. 2020; p. 8).

However, the online retail channel is not without risks. Forsythe and Shi (2003) identified four risks related to data privacy and security, website glitches, and product performance. The first three risks are associated with the online ordering process and, therefore, are the same for BOPS and online-only customers. However, the product performance risk is reduced for BOPS customers due to the opportunity to physically examine the product during pick up (Chatterjee 2010; Herhausen et al. 2015; Kim et al. 2017). In addition to risk reduction motivations, BOPS customers visit the store for efficiency-related reasons such as avoiding shipping fees and getting the items quickly compared to having them delivered (Chatterjee 2010; Kim et al. 2017).

TPB provides additional insights into the differences between BOPS customers and online-only retail customers. According to TPB, perceived behavioral control is a determinant of both intentions and actual behaviors (Ajzen 1985). Ajzen and Madden (1986) found evidence for direct effects of perceived behavioral control on goal-directed behaviors as well as indirect effects through intentions. In other words, TPB suggests that people are much more likely to form intentions and enact goal-directed behaviors when they feel that they can do so successfully. This provides another rationale for why customers choose the BOPS service; once an item is purchased online, it is guaranteed to be in the store for pick up - typically the same day - and available for inspection and immediate return if necessary, thereby enabling goal achievement (Gollwitzer 1993). This is in contrast to online-only retail shoppers who must wait for product delivery, with additional risks that the product will be lost or stolen during the delivery process. Only after delivery can these customers determine if products are in good condition and meet their needs. In essence, BOPS customers are using the offline channel "to gather (more) complete information about the process that might not be available when only one (online) channel is used" (Acquila-Natale and Iglesias-Pradas 2020; p. 46).

Overall, while both BOPS and online-only customers value the efficiency of the online channel for the front-end of the process, their perspectives diverge at the back-end of the process. Online-only customers are willing to take greater product performance risk for the convenience of home delivery. In contrast, BOPS customers reduce product performance risk by picking up in-store and achieve some cost and delivery speed efficiencies, but endure the inconvenience of traveling to the store. The choice of how to balance efficiency and risk reduction in the delivery process is what distinguishes BOPS and online-only customers.

More generally, the primary purposes of customers using BOPS are mostly utilitarian - to save effort, time, and money, and reduce risk (Chatterjee 2010; Kim et al. 2017). However, because part of the shopping process for BOPS customers is offline, we briefly consider how they compare with conventional retail shoppers. In contrast to BOPS customers, conventional retail shoppers are motivated not only by utilitarian purposes but also by hedonic reasons. They seek and feel enjoyment in their retail experience. For instance, people go shopping to get stimulated and excited, socialize with their friends and family, or relieve stress and alleviate their mood. While efficiencyseeking BOPS customers drop by the store quickly, conventional shoppers wander around the store, spend more time, interact with employees and other customers, and feel the atmosphere of the store to satisfy their hedonic goals (Arnold and Reynolds 2003). Thus, in-store shoppers perceive and interact with service components holistically, co-creating cognitive, affective, physical, and social experiences in the service encounter (Bustamante and Rubio 2017).

\subsection{BOPS service quality}

Service quality is defined as "a global judgment, or attitude, relating to the superiority of a service" (Parasuraman et al. 1988; p. 16). This concept has been studied extensively during the past 30 years as a primary antecedent of customer 
satisfaction and loyalty intentions (Taylor and Baker 1994; Zeithaml et al. 1996; Baker and Crompton 2000; Cronin et al. 2000; Caruana 2002). Recent research on BOPS similarly supports the impact of BOPS service attributes on outcomes of value to retailers and customers. Behavioral studies on BOPS customers discovered that time-pressure, price-consciousness, innovation characteristics, perceived online risk, location convenience, and product involvement are primary influencers of customer decisions to use BOPS (Chatterjee 2010; Kim et al. 2017). BOPS usage, in turn, was shown to positively influence purchase size, repurchase intention, and purchase deferral (Chatterjee 2010). Specifically, Song et al. (2020) found that BOPS usage increases both the purchase amount of online shopping and the purchase frequency of offline shopping. They also showed that offline store characteristics (i.e., store density, product variety, competition) moderate these benefits of BOPS on purchase behaviors. Studies from the operational perspective indicate that BOPS implementation positively influences store traffic and offline store sales (Gallino and Moreno 2014; Gao and Su 2016; Akturk et al. 2018). Moreover, Jara et al. (2018) suggest that accurate stock-out information, dual experiences of website and pick-up service, and pleasant interactions with employees can create long term value for BOPS customers.

Due to its important relationship with customer satisfaction and loyalty intentions, much research has been devoted to identifying and measuring service quality dimensions. Parasuraman et al. (1988) developed SERVQUAL, the first comprehensive five-dimension scale for service quality. SERVQUAL has been tested and adapted for diverse industries (Babakus and Boller 1992; Babakus and Mangold 1992; Cronin and Taylor 1992). In the retail context, studies have examined service quality specific to different channels such as traditional offline retail or the newer online channel. For example, for the traditional offline retail channel, Dabholkar et al. (1996) modified SERVQUAL to measure retail service quality. For online retail, scholars have proposed various scales that include dimensions ranging from website design to shopping efficiency (Barnes and Vidgen 2002; Parasuraman et al. 2005; Loiacono et al. 2007).

However, within the retail domain, studies on the dimensions of BOPS service quality are scarce. Swaid and Wigand (2012) proposed a scale for site-to-store quality, comprised of seven dimensions: information quality, website reliability, responsiveness, assurance, website efficiency, personalization, and integrated-pickup. However, they considered BOPS as "online-focused shopping" and concentrated mostly on the process before pick-up. Pick-up service quality was simplified into a single dimension, integrated pick-up, which failed to capture the diverse aspects of offline BOPS service quality. Another study by Murfield et al. (2017) focused on the BOPS logistics service quality. They showed that consumer satisfaction and loyalty response are determined by the availability, condition, and timeliness dimensions of BOPS logistics.

The development of a BOPS scale focusing specifically on the pick-up service quality (BOPS-PU-QUAL) adds to this emerging literature by addressing the critical offline portion of the BOPS process in greater depth and explicitly considering the motivations, expectations, and responses of BOPS customers. In addition, it provides retail store managers with a better understanding of how BOPS customers perceive offline service quality to help guide management of the instore part of the BOPS process.

\section{Scale development}

The primary objective of this study is to develop a comprehensive service quality (QUAL) scale for the in-store pick-up (PU) service of BOPS. We followed the rigorous multi-step procedure suggested by the conventional guidelines for scale construction (Churchill 1979; Hinkin 1998). Our scale development process is visually summarized in Fig. 1.

\subsection{Item generation}

\subsubsection{Data collection}

To identify the key attributes of BOPS-PU-QUAL, initial items were generated through a qualitative study using the critical incident technique (CIT) (Flanagan 1954). CIT gathers, analyses, and classifies the events that make significant contributions to the success or failure of an activity (Bitner et al. 1990). This technique frequently appears in service research as a tool to identify the sources of customer satisfaction and dissatisfaction. It is used either independently to interpret and categorize constructs or in combination with other methods to assist quantitative research such as scale development and scenario experiments (Gremler 2004). CIT research is conducted through various media, including e-mail, short interviews, and online surveys (Bitner et al. 1990; Cassab and MacLachlan 2009; Zhang et al. 2018).

Our data collection was carried out through an online selfadministered survey using Amazon's Mturk for 10 days from May 24, 2018, to June 2, 2018. Only those who used BOPS service in the preceding 12 months and could recall either a particularly satisfying or dissatisfying BOPS experience were invited to participate in the survey. The resident location of the survey participants was set to the United States because it has the largest retail market (Euromonitor International 2018), and its retailers use the most advanced and diverse omnichannel strategies (Schmaus et al. 2017). CIT questions were adopted from CIT literature in the field of service and modified to fit 
the current research context (Bitner et al. 1990; Hoffman et al. 1995; Meuter et al. 2000).

Participants were first asked to describe a satisfying or dissatisfying incident with BOPS. Respondents were assisted in recalling the incident through a few incident profiling questions about the retailer and products involved in the incident. Next, they answered questions on the circumstances that led to the incident, details of what happened during the incident, and outcomes of the incident. Lastly, personal profiling questions were asked.

\subsubsection{Initial item generation}

We obtained 108 valid responses and incidents $(67.1 \%$ valid response rate) - 52 satisfactory and 56 unsatisfactory experiences. Since categories can be built with 50 incidents and the reliability of categorization is enhanced with over 100 incidents (Lockwood 1994), our sample size was deemed sufficient. The final sample seemed to represent BOPS customers in practice well. Gender was evenly distributed - men $(51.9 \%)$ and women $(48.1 \%)$ - and the majority $(72.2 \%)$ of respondents were between the ages of 20 and 39 years. This age distribution corresponds with the existing knowledge that BOPS customers are younger than average in-store shoppers (Jara et al. 2018). Most (83.3\%) of respondents have used BOPS twice or more during the last year.
To generate initial items, data were subjected to content analysis following the suggestions in the literature (Krippendorff 1980). Respondents' descriptions of critical incidents were unitized and coded into service attributes using MAXQDA software. Items were generated both inductively from the content analysis of the incidents themselves and deductively from the relevant quality dimensions of existing service quality scales, considering the theoretical differences among BOPS customers, online-only customers, and conventional in-store shoppers. Referenced scales include SERVQUAL (Parasuraman et al. 1988), third-order factor model of service quality (Brady and Cronin 2001), retail service quality (Dabholkar et al. 1996), logistics service quality (Mentzer et al. 2001), multichannel customer evaluation (Cassab and MacLachlan 2009), multichannel integration quality (Wu and Chang 2016), and site-to-store quality (Swaid and Wigand 2012). Relevant service quality scales and their dimensions are presented in Table 1.

Next, five service researchers evaluated the adequacy of items by examining whether the items clearly reflect the meaning of the responses to our CIT survey. They also commented on the initial sorting and expressions of items. The expressions of items were modified to fully and clearly represent actual responses. As a result, a set of 60 items was extracted and classified into seven initial dimensions: employee interaction, store environment, time required for pick-up, pick-up policy / process, order/item condition, channel integration, and problem-handling.
Fig. 1 The process of BOPS-PU-QUAL scale development

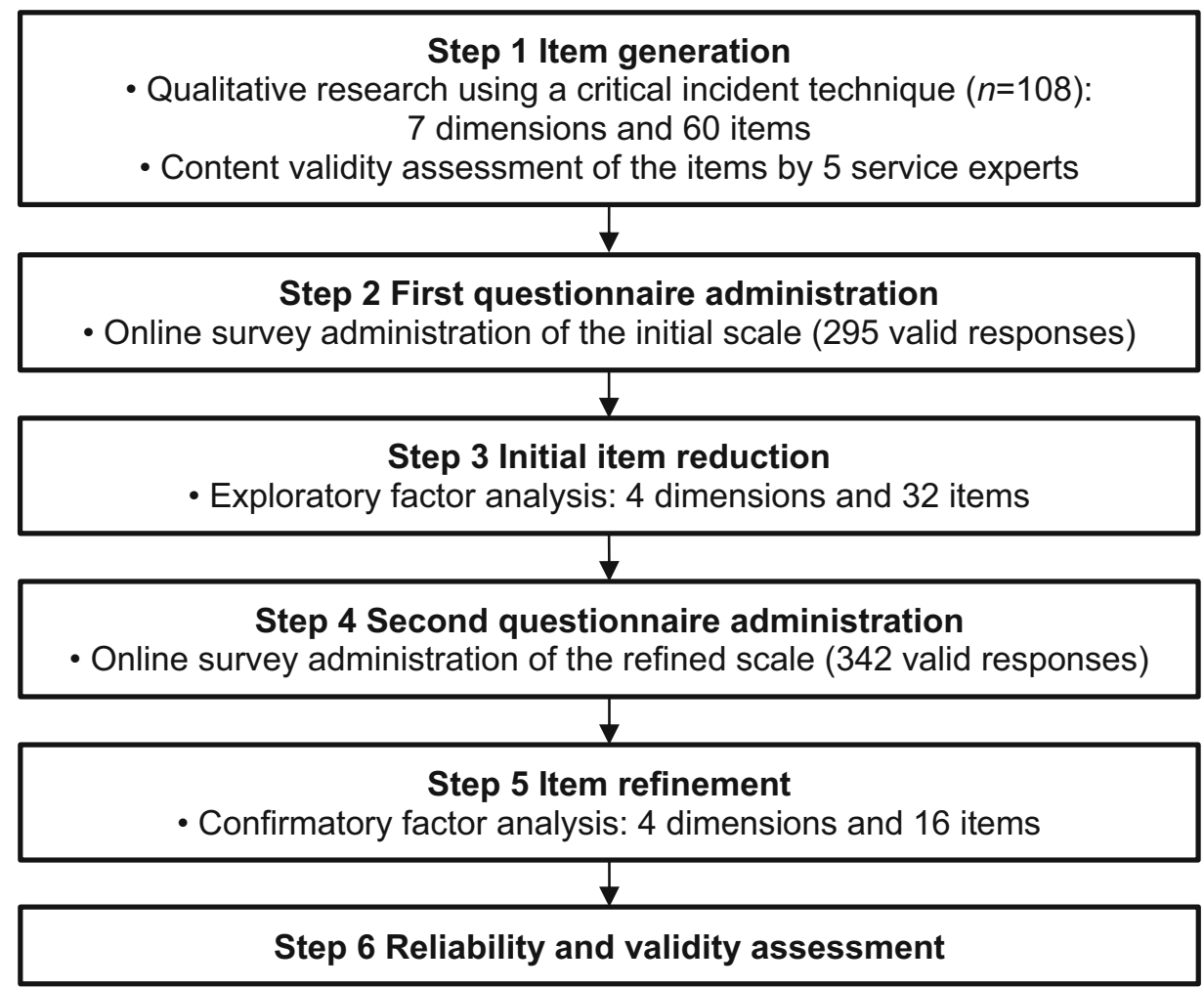


Table 1 Relevant service quality scales

\begin{tabular}{|c|c|c|}
\hline Type & Scale & Dimensions \\
\hline \multirow[t]{3}{*}{ Offline } & SERVQUAL Parasuraman et al. (1988) & Tangibles, reliability, responsiveness, assurance, empathy \\
\hline & $\begin{array}{l}\text { Third-order factor model of service } \\
\text { quality Brady and Cronin (2001) }\end{array}$ & $\begin{array}{l}\text { Interaction quality (attitude, behavior, expertise), physical } \\
\text { environment quality (ambient conditions, design, social } \\
\text { factors), outcome quality (waiting time, tangibles, valence) }\end{array}$ \\
\hline & $\begin{array}{l}\text { Retail service quality scale (RSQS) } \\
\text { Dabholkar et al. (1996) }\end{array}$ & $\begin{array}{l}\text { Physical aspects (appearance, convenience), reliability } \\
\text { (promises, doing it right), personal interaction (inspiring } \\
\text { confidence, courteous/helpful), problem solving, policy }\end{array}$ \\
\hline Logistics & $\begin{array}{l}\text { Logistics service quality (LSQ) } \\
\text { Mentzer et al. (2001) }\end{array}$ & $\begin{array}{l}\text { Personal contact quality, order release quantities, information } \\
\text { quality, ordering procedures, order accuracy, order condition, } \\
\text { order discrepancy handling, order quality, timeliness }\end{array}$ \\
\hline \multirow[t]{4}{*}{ Multi/Omnichannel } & $\begin{array}{l}\text { Multichannel evaluation Cassab and } \\
\text { MacLachlan (2009) }\end{array}$ & Problem handling, record accuracy, scalability, usability \\
\hline & $\begin{array}{l}\text { Multichannel integration quality } \\
\text { Wu and Chang (2016) }\end{array}$ & $\begin{array}{l}\text { Transparency of service configuration, information } \\
\text { consistency, business ties, process consistency }\end{array}$ \\
\hline & $\begin{array}{l}\text { Omnichannel retail service quality } \\
\text { Zhang et al. (2019) }\end{array}$ & $\begin{array}{l}\text { Store appearance, personal interaction, efficiency, aesthetic } \\
\text { design, privacy/security, customization, integration, } \\
\text { fulfilment/reliability }\end{array}$ \\
\hline & $\begin{array}{l}\text { Multichannel retail service quality } \\
\text { Acquila-Natale and Iglesias-Pradas }(2020)^{\mathrm{a}}\end{array}$ & $\begin{array}{l}\text { In-store experience, reliability and fulfillment, service provision } \\
\text { policies, customer service }\end{array}$ \\
\hline BOPS & Site-to-store quality Swaid and Wigand (2012) & $\begin{array}{l}\text { Website efficiency, information quality, website reliability, } \\
\text { responsiveness, assurance, personalization, integrated-pickup }\end{array}$ \\
\hline
\end{tabular}

${ }^{\text {a }}$ Note: These scales were not referenced in the scale development process due to their recency

\subsection{Initial item reduction}

The preliminary measurement scale with 60 items was administered for initial item reduction. An online survey was conducted using Mturk from July 17, 2018, to August 31, 2018. Respondents were asked to think of a retail brand's BOPS service with which they are most familiar and evaluate their past BOPS pick-up experiences with that specific retailer by answering our questions using a 7-point Likert scale.

A total of 295 valid responses were obtained (39.7\% valid response rate). Respondents were relatively evenly distributed in gender - 139 men $(47.1 \%)$ and 156 women $(52.9 \%)$ - and the majority (76.9\%) of respondents were between the ages of 20 and 39 years. Most (84.1\%) of the respondents had used BOPS twice or more during the last 12 months, and $65.1 \%$ have used the BOPS service of a superstore.

An exploratory factor analysis (EFA) was conducted using SPSS 25 software to reduce initial items. Responses to questions in the problem-handling dimension showed some missing data because some respondents lacked relevant experiences to evaluate the quality of problem-handling. To deal with this issue, we adopted the matrix of expectation maximization (EM) correlations method (Graham 2009) and utilized the SPSS syntax and macro written by Weaver and Maxwell (2014). We used principal axis factoring as the extraction method and Promax (oblique rotation) as the rotation method. Using Kaiser (1960)'s criterion, factors with an eigenvalue of greater than one were identified.
In the process of conducting multiple iterations to remove items until we found a meaningful pattern matrix, 28 items that had (1) communalities below .40, (2) factor loading below .40 , or (3) cross-loadings of .40 or above were deleted (Hair et al. 1998). As a result, 32 items in 4 dimensions were retained. The Kaiser-Meyer-Olkin (KMO) value (.96) and Bartlett's test of sphericity $(p<.01)$ indicated an appropriate sample size and intercorrelations of items. Each factor was composed of at least three items (Zwick and Velicer 1986), and all items had inter-item correlations above .40 (Kim and Muller 1978). The identified factors accounted for $66.83 \%$ of the total variance (Hair et al. 1998). The initial BOPS-PUQUAL scale demonstrated a high level of internal consistency with a high Cronbach's alpha value for the BOPS-PU-QUAL scale $(\alpha=.98)$ and factors (ranging from .82 to .97$)$ (Nunnally 1978). Extracted factors include service effectiveness (15 items), problem-handling ( 9 items), ease of access (5 items), and item quality (3 items).

\subsection{Item refinement}

Another data set was collected for a confirmatory factor analysis (CFA) using the reduced BOPS-PU-QUAL scale with 32 items. A self-administered online survey, available for 4 days starting on September 7, 2018, followed the same procedure as the earlier survey for EFA. This survey included questions for customer response variables to assess BOPS-PU-QUAL's predictive and nomological validity. Two items from Brady 
and Cronin (2001) were used for perceived BOPS service quality (i.e., "I would say that this retail brand provides superior BOPS service," and "I believe that this retail brand offers excellent BOPS service"). BOPS service satisfaction was measured with two items from Szymanski and Hise (2000) (i.e., "Overall, how do you feel about this retail brand's BOPS service? very satisfied - very dissatisfied; very pleased - very displeased"). Finally, Dabholkar and Bagozzi (2002)‘s items for the reuse intention measured the intention to use the retail brand's pick-up service again (i.e., "Would you use this retail brand's BOPS service again? likely - unlikely; possible - impossible").

A total of 342 valid responses were collected $(51.7 \%$ valid response rate) and analyzed. The demographic characteristics of this sample were similar to those of the previous samples.

We conducted a CFA using AMOS 18.0 software. Missing data were imputed using the expectation maximization method. To obtain an acceptable fit, we removed 16 items with high modification indices, including nine items of service effectiveness, five items of problem handling, and two items of ease of access. The final scale consisted of 16 items in four dimensions. The refined model showed an acceptable model fit $\left(\chi^{2}=269.44, d f=93, p<.01 ; C F I=.96, T L I=.95\right.$, $N F I=.94$, RMSEA = .08) (Bagozzi and Yi 1988; MacCallum et al. 1996). All factor loadings were above .60 and significant at $p<.01$, suggesting that the items appropriately reflect the dimensions.

The final scale demonstrated a high level of internal consistency with high Cronbach's alpha values for the BOPS-PUQUAL scale $(\alpha=.95)$ and all factors (ranging from .83 to .94) (Nunnally 1978). Composite reliability values were all well above 60 (Bagozzi and Yi 1988). Convergent and discriminant validity were assessed by the procedures suggested by Fornell and Larcker (1981). The average variance extracted (AVE) for each construct was well above .50, confirming convergent validity. All square root values of AVE were larger than the absolute values of inter-construct correlations, demonstrating discriminant validity. To assess predictive validity, we correlated a conceptually related measure - perceived service quality - with the BOPS-PU-QUAL scale. The construct was correlated with the mean scores of the four BOPS-PU-QUAL dimensions. All correlations were positive and statistically significant $(p<.01)$, ranging from .55 to .80 . The CFA and validity test results are summarized in Tables 2 and 3 , respectively.

\subsection{Dimensions of BOPS-PU-QUAL}

\subsubsection{Service effectiveness}

The dimension of service effectiveness is defined as the extent to which the pick-up is quick, convenient, and pleasant. Items reflect whether the staffing or resource levels are sufficient to serve BOPS customers promptly and whether services are convenient and pleasant for customers. Responses from our CIT survey illustrate incidents of success and failure in this dimension.

"I was served quickly and efficiently. There was no line,
so I was served immediately. I only had to wait for about
a minute before my order was brought to me. The pick-
up time was very short. It was only a couple of minutes."

"I waited longer for someone to help me than I would have liked. Then, the employee was not able to find the product very quickly. She had to look around quite a while for it."

This dimension reflects the emphasis of extant research on time and convenience as significant values of BOPS and multichannel services. For example, Chatterjee (2010) found that time-pressure is a primary factor motivating customers to use BOPS service, and Schröder and Zaharia (2008) identified convenience orientation as a motivation for multichannel usage. Since multichannel customers expect and believe that multiple channels allow them to organize their shopping process in a comfortable, easy, and effortless way (Verhoef et al. 2007), BOPS pick-up service should meet this expectation.

\subsubsection{Problem-handling}

The dimension of problem-handling refers to satisfactorily addressing problems BOPS customers face. Items reflect whether BOPS issues such as order discrepancies, including the ones caused during online shopping, are handled directly during pick-up, and whether employees are sympathetic and prompt when handling problems. Responses from our CIT survey illustrate incidents of success and failure in this dimension.

"One item of my order wasn't in stock, but they (store employees) went out of their way to find me something very close that didn't show up online. They gave me the product that was a step up from the one I actually ordered for a discounted price. They wanted to make me happy."

"I went to pick up the item, and it seemed to have been severely damaged during shipping. I complained, but the employee wasn't interested in addressing the issue and said I needed to do an online chat with the service online. They (online service) told me that this was wrong, and I had to report it when picking up. I told them I did, and they sent me back to the store. The item was in such bad condition that the store didn't even take it back when I drove back, making jokes about how I must have run over it with a car." 
Table 2 CFA results for BOPS-PU-QUAL scale

1 Service effectiveness

.94

.94

.83

.89

good service to BOPS customers

E2 Employees are able to serve me quickly

E3 Employees are ready to serve me immediately when I arrive at the pick-up counter

E4 The store dedicates sufficient resources for pleasant pick-up experience of customers

E5 Once it is my turn to be served at the pick-up counter, it takes

no time for me to receive what I ordered

E6 The store provides adequate services to enhance the convenience of BOPS customers particularly

2 Problem-handling

P1 During pick-up, the store directly and immediately handles problems including the ones that were caused during online shopping

P2 The way the pick-up counter in this store handles order discrepancies is satisfactory

P3 When I face a problem, employees are sympathetic

P4 Employees quickly handle problems when they occur

3 Ease of access

A1 The pick-up counter is easy to find

A2 The pick-up counter is located for easy access

A3 This store allows me to pick up my items as instructed online

4 Item-quality

I1 The store ensures that pick-up packages are never damaged

I2 The store ensures that pick-up items are never damaged
I3 The store keeps pick-up items in the proper storage conditions

${ }^{\mathrm{ab}}$ Note: Standardized loading; Average variance extracted

The ability to promptly solve problems related to items purchased online in the offline store is one of the unique benefits of BOPS service that differentiate it from online-only service (Bell and Howell 2017). Hence, the offline store's ability to solve BOPS problems can serve as a critical determinant of
BOPS pick-up service quality. Examples of these BOPS problems include errors that occurred during online purchase such as a "ready for pick-up" confirmation sent by the online channel when in reality the item is unavailable in the offline store. A failure in handling BOPS problems might indicate a failure
Table 3 Inter-construct correlation matrix and predictive validity for BOPS-PU-QUAL

\begin{tabular}{lcccc}
\hline & Service effectiveness & Problem-handling & Ease of access & Item-quality \\
\hline BOPS-PU-QUAL dimensions & & & \\
Service effectiveness & $\mathbf{8 5}$ & $\mathbf{. 8 3}$ & \\
Problem-handling & .80 & .55 & $\mathbf{. 8 2}$ \\
Ease of access & .64 & .70 & .61 & $\mathbf{. 8 2}$ \\
Item-quality & .69 & .66 & .56 & .55 \\
Perceived service quality & .83 & & \\
\hline
\end{tabular}

Note: All correlation values are significant at $\mathrm{p}<.01$. Values in the diagonal (in bold) are the square roots of AVE. 
in online-offline integration, which is a critical service attribute of multichannel services (Sousa and Voss 2006).

Problem-handling has been suggested as an essential attribute in existing quality scales for retail and multichannel services. While developing a service quality scale unique to retail services, Dabholkar et al. (1996) added the problemsolving dimension to the existing SERVQUAL scale to reflect retail customers' sensitivity to the service provider's willingness to resolve problems and complaints promptly. The multichannel customer evaluation measurement by Cassab and MacLachlan (2009) also includes the problem-handling aspect as a key dimension.

\subsubsection{Ease of access}

Ease of access refers to the ease of offline pick-up. Two items relate to easy and convenient access to the pick-up counter, and the third item concerns whether pick-up in the store is carried out as instructed online. Together, three items reflect whether the transition from online shopping to offline pick-up is well facilitated, so that customer confusion is minimized, and customers' omnichannel shopping journeys are smooth. One example of customer responses relating to this dimension is as follows:

"After ordering online, I went to the store upon receiving an e-mail notification that my ordered items had arrived. The store had a designated area for pick-up near the entrance to the store. I told the clerk (who was already present in the area) that I came to pick up my online order. She scanned a barcode from my phone and handed my order to me. (...) It was a very simple pick-up process."

Another response illustrates a failure incident due to information discrepancy between online instructions and the actual offline pick-up process.

"My e-mail informed me that the order would be ready within one hour. Soon, I received another e-mail telling me that my items were ready to be picked up. In about 2 hours in total after I placed an online order, I went to the store to pick up my items. I reached the counter only to be told by the cashier that my order items were not ready."

This dimension is consistent with the findings of the study by Kim et al. (2017), which showed that the access convenience of the store positively moderates the effect of perceived innovation characteristics and online risk on a customer's intention to BOPS. Also, the last item of this dimension (i.e., "This store allows me to pick up my items as instructed online") reflects the importance of information consistency between online and offline stores, as suggested by studies on multichannel integration quality (Sousa and Voss 2006; Wu and Chang 2016). That is, the information generated in both channels should be consistent in order to support the customer's seamless shopping journey.

\subsubsection{Item-quality}

Item-quality refers to the condition of items and packages. It relates to the quality of the core service outcome of BOPS ordered items ready to be picked up in good condition as a result of having been well packaged and stored. An example response describing a failure in this dimension is as follows:

"I inspected it (the purchased item) and was shocked at how bad the condition of the product was. I am not sure how, but the packaging box was completely ruined. It had dents, holes, and rips, which resulted in the removal of some information printed on the box."

Ensuring item-quality is important because it reduces the shopping risk of BOPS, compared to that of online-only shopping, and is one of the primary values BOPS offers. BOPS attracts people who perceive high risk in online-only shopping (Kim et al. 2017), and the motivation to eliminate the risk drives customers' use of multiple channels (Schröder and Zaharia 2008). This dimension also corresponds to the order condition dimension of logistics service quality, which measures whether the delivered item was intact without damage (Mentzer et al. 2001). However, our scale's item-quality dimension extends the order condition dimension by including not only the quality of delivered items but also the quality of an item's package and storage condition (i.e., "The store ensures that pick-up packages are never damaged," and "The store keeps pick-up items in the proper storage condition").

\subsection{Relative importance of BOPS-PU-QUAL dimensions}

To examine the extent to which each BOPS-PU-QUAL dimension contributes to perceived service quality and satisfaction, we conducted multiple regression analyses with SPSS 25 . Due to potential multicollinearity issues when using mean scores in the regressions, factor scores of items in each of the four dimensions served as independent variables (Neter et al. 1996). Table 4 summarizes the regression analysis results.

We conducted regression analyses following the procedure taken in Parasuraman et al. (2005)'s E-S-QUAL scale development. Factor scores were computed using a principal component analysis with orthogonal rotation method (varimax). All items loaded on appropriate factors, and four factors accounted for $77.66 \%$ of the total variance. Multiple regression analysis outcomes showed that all dimensions 
significantly affected perceived service quality and satisfaction. The service effectiveness dimension had the strongest impact on both dependent variables $(\beta=.68, p<.01$ for perceived service quality; $\beta=.63, p<.01$ for satisfaction), followed by problem-handling $(\beta=.35, p<.01$ for perceived service quality; $\beta=.42, p<.01$ for satisfaction), ease of access ( $\beta=.26, p<.01$ for perceived service quality; $\beta=.26, p<.01$ for satisfaction), and item-quality $(\beta=.21, p<.01$ for perceived service quality; $\beta=.20, p<.01$ for satisfaction).

\subsection{Nomological validity of BOPS-PU-QUAL}

To test the nomological validity of BOPS-PU-QUAL, a structural equation model was formulated to test its effect on satisfaction and reuse intention for the brand's BOPS. We modeled BOPS-PU-QUAL as an exogenous construct that affects the higher-order constructs of BOPS satisfaction and behavioral intention. The conventional model of "service quality $\rightarrow$ satisfaction $\rightarrow$ behavioral intention" was formulated (Parasuraman et al. 1985; Cronin and Taylor 1992; Baker and Crompton 2000). The constructs were set as latent constructs that are represented by corresponding measurements. BOPS-PU-QUAL was treated as a second-order latent construct serving each dimension of BOPS-PU-QUAL as the first-order constructs, which in turn are represented by 16 items. Figure 2 shows the model.

The model showed acceptable incremental fit indices, although the RMSEA values indicated a mediocre fit $\left(\chi^{2}=\right.$ 513.42, $d f=158, p<.01, C F I=.94, T L I=.93, N F I=.92$, $R M S E A=.08)$. All paths from BOPS-PU-QUAL to BOPS satisfaction $(b=.99, S E=.06)$, from BOPS satisfaction to reuse intention $(b=.45, S E=.09)$, and from BOPS-PU-QUAL to reuse intention $(b=.27, S E=.10)$ were significant $(p<.01)$. Thus, the nomological validity of the BOPS-PU-QUAL was also confirmed. Additionally, a bootstrapping method was applied to confirm the mediation effect (MacKinnon et al. 2004). One thousand bootstrap samples were created by using the maximum likelihood method. Confidence intervals were set to $95 \%$, and bias-corrected bootstrap confidence intervals were used (Cheung and Lau 2008). Bootstrap estimates indicated a full mediation effect of BOPS satisfaction in the relationship between BOPS-PU-QUAL and BOPS reuse intention. The unstandardized indirect effect of BOPS-PU-QUAL on the reuse intention was $.44(p<.01)$ while the direct effect was .17 $(p>.05)$.

\section{Discussions and conclusions}

\subsection{Summary and discussion}

In this study, we developed a multidimensional scale for the pick-up service quality of the Buy-Online-Pick-up-in-Store (BOPS). First, 60 initial items were drawn from a qualitative study using the critical incident technique as well as an extensive review of relevant literature. Second, exploratory factor analysis was conducted with the data collected through a survey for initial item reduction. Third, the final scale consisting of 16 items in 4 dimensions was finalized through confirmatory factor analysis with another set of survey data.

Our BOPS-PU-QUAL scale suggests that a well-designed BOPS pick-up service should allow customers to easily and conveniently reach the pick-up counter and pick up items in good condition quickly, smoothly, and agreeably with sufficient staff and through services dedicated for BOPS pick-up. Furthermore, problems customers may face during pick-up, regardless of whether they were caused by the online or offline channel, should be resolved promptly and pleasantly during pick-up.

The four dimensions of BOPS-PU-QUAL indicate that BOPS customers are concerned mostly with functional attributes rather than experiential attributes. In fact, initial items related to experiential attributes were eliminated during the scale development process. BOPS-PU-QUAL includes items related to employee attitude only in the context of problemhandling (i.e., "When I face a problem, employees are
Table 4 Regression analysis results for BOPS-PU-QUAL dimensions

\begin{tabular}{lcc}
\hline & \multicolumn{2}{l}{ Regression coefficients (standard error) } \\
\cline { 2 - 3 } & Perceived service quality & Satisfaction with BOPS \\
\hline BOPS-PU-QUAL dimensions & & \\
Service effectiveness & $1.03(.05)$ & $.89(.04)$ \\
Problem-handling & $.52(.05)$ & $.58(.04)$ \\
Ease of access & $.38(.05)$ & $.37(.04)$ \\
Item-quality & $.31(.05)$ & $.28(.04)$ \\
F & 193.16 & 179.84 \\
$\mathrm{R}^{2}$ & .70 & .68 \\
Adjusted $\mathrm{R}^{2}$ & .69 & .68 \\
\hline
\end{tabular}

Note: All coefficients are significant at $p<.01$ 


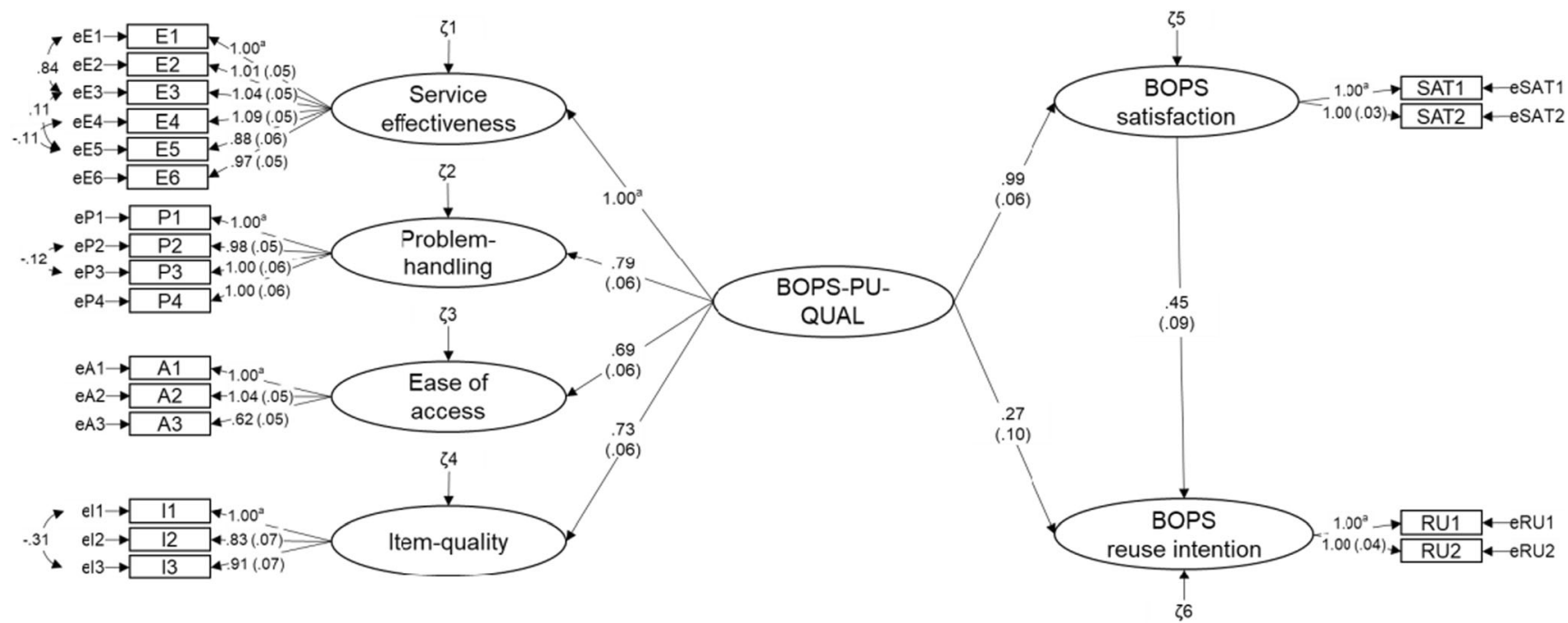

Fig. 2 The structural model for BOPS-PU-QUAL nomological validity. Note: Numbers on paths represent unstandardized coefficients and standard errors (in parenthesis). All coefficient estimates are significant at $p<.01$. ${ }^{\text {a }}$ Paths are given the fixed weight of 1

sympathetic"). Our study results demonstrate that BOPS customers focus on service aspects that satisfy utilitarian needs for using BOPS (McCabe et al. 2007). Similar to online retail customers, BOPS customers are highly interested in receiving quick, efficient, and convenient service (Barnes and Vidgen 2002; Parasuraman et al. 2005). Our proposed dimensions also reflect how BOPS customers balance efficiency and risk reduction. The item-quality dimension is focused on the condition of items and packaging, which relates to "reducing product performance risk" associated with online shopping (Forsythe and Shi 2003). The problem-handling dimension suggests the importance of immediately solving problems that arise during the pick-up service.

While our scale does not propose channel integration quality as a separate dimension, it still supports the importance of seamless integration of channels suggested by prior multichannel retail literature (Sousa and Voss 2006; Wu and Chang 2016; Zhang et al. 2019). Instead, channel integration quality is reflected in two relevant dimensions - problemhandling and ease of access. The item, "During pick-up, the store directly and immediately handles problems including the ones that were caused during online shopping," in the problem-handling dimension indicates the retailer's ability to solve issues from both channels effectively during store pickup. Three items of the ease of access dimension address channel integration quality by evaluating the smooth transition from online channel to offline channel (i.e., "The pick-up counter is easy to find," "The pick-up counter is located for easy access," and "This store allows me to pick up my items as instructed online"). In particular, the third item, "This store allows me to pick up my items as instructed online," reflects the information consistency in channels, which is defined as an element of channel integration quality (Sousa and Voss 2006; Wu and Chang 2016). Our initial set of items included two items related to channel integration that were eliminated during the scale development process: "The time between placing an order and the item becoming available in the store for pick-up is short," and "Items are ready for pick-up in the store by the time promised during my online purchase."

The regression analysis showed that service effectiveness is the most crucial BOPS dimension, followed by problem-handling, ease of access, and item quality. This result emphasizes the importance of offering quick and smooth pick-up service and is consistent with a consumer report in which consumers selected "quick in and out experience" (56\%) as the top attribute of a good pick-up-in-store experience (Bell and Howell 2017). The service effectiveness dimension incorporates the top service attributes discussed in the report (i.e., quick in and out service, no waiting in line, and dedicated resources to serve BOPS customers in particular).

The full mediation of BOPS satisfaction in the relationship between BOPS-PU-QUAL and BOPS reuse intention is consistent with the service quality literature. Extant studies suggest that service quality influences behavioral intentions with satisfaction as a full or partial mediator (Cronin et al. 2000; Caruana 2002; Olorunniwo et al. 2006). While some studies have indicated a direct effect of service quality on behavioral intentions (Taylor and Baker 1994; Zeithaml et al. 1996), Olorunniwo et al. (2006) discovered that the indirect effect of service quality through service satisfaction is much larger than its direct effect in evoking favorable behavioral intentions.

\subsection{Academic contributions}

This study extends the stream of research on omnichannel service quality and makes the following specific contributions. First, we developed BOPS-PU-QUAL, a 
comprehensive scale for BOPS pick-up service quality. This scale reflects the uniqueness of BOPS customers, who are online customers by nature but choose the physical store as a delivery option. Specifically, this scale offers a deeper understanding of the BOPS pick-up service quality, which is differentiated from the understanding of general multichannel retail service quality addressed by existing scales (Cassab and MacLachlan 2009; Swaid and Wigand 2012; Wu and Chang 2016; Zhang et al. 2019). The dimensions of our scale reflect the values that BOPS service offers to online customers, illustrating which areas of pick-up service constitute the customer evaluation of the BOPS service.

Second, this study empirically demonstrates the importance of offline service quality in the omnichannel retail context. BOPS-PU-QUAL positively and significantly influences perceived service quality, service satisfaction, and reuse intention of BOPS service. These results indicate that the service quality of the offline portion of the omnichannel service influences customers' reactions towards not only the offline pick-up store but also the entire BOPS service. Extant research has suggested that the intimacy of physical interactions in the physical store may serve as the point of differentiation for omnichannel retailers against online-only retailers (Bell et al. 2018). However, the intimacy of physical interaction is double-edged because offline failures can yield a greater negative impact on customer satisfaction and behavioral intention than online failures (Harris et al. 2006). Our study results extend this discussion by demonstrating the impact of the offline pick-up service quality on the customer's intention to reuse BOPS service.

Third, this research confirms the role of BOPS satisfaction as a mediator in the impact of BOPS pick-up service quality on behavioral intentions in the omnichannel context. The service quality literature in conventional contexts broadly accepts service satisfaction as a robust mediator (Cronin et al. 2000; Caruana 2002; Olorunniwo et al. 2006). This study is the first to show this "service quality $\rightarrow$ satisfaction $\rightarrow$ behavioral intention" path in the omnichannel context, extending the knowledge into this developing area.

\subsection{Managerial contributions}

This study offers several managerial insights into omnichannel retailers. First, we demonstrated the importance of carefully managing the offline service quality of BOPS. Investing in technology to serve customers through new omnichannel services like BOPS can be expensive. While the implementation of BOPS requires retailers to adopt new technologies and integrate the process, organization, and communication of the channels, BOPS implementation may not result in desired outcomes unless the firm is ready to offer a high-quality pick-up service to customers.

Second, BOPS-PU-QUAL provides specific guidelines on managing BOPS pick-up service. Notably, it helps managers to better determine the priorities in managing different dimensions of BOPS pick-up service quality. Firms should first achieve service effectiveness, or quick and smooth pick-up service. Specific recommendations for establishing quality BOPS pick-up service can be inferred from our scale. For example, installing a separate pick-up counter near the main entrance with enough staff is recommended, and employees need to be well trained to assist with quick pick-ups and solve problems that arise during the BOPS process.

The scale also suggests that retailers introduce dedicated services for BOPS customers. For instance, leading retailers such as Walmart and Target reserve designated parking spots for the convenience of BOPS customers. Moreover, we recommend that managers adopt additional services to enhance the ease of access and service effectiveness of pick-up. For example, delivery-to-car service allows customers to stay in the parking lot without walking into the store to pick up their items.

Moreover, the finding that BOPS-PU-QUAL is composed of functional service attributes rather than experiential attributes agrees with the recent introduction of self-service technologies for BOPS pick-up service. Implementing pick-up lockers or towers to facilitate easy and convenient pick-up might be an effective strategy for enhancing BOPS satisfaction. An automated pick-up process offers quick pick-up without having to interact with humans. This self-service pick-up enhances the functional service quality while eliminating the experiential portion of the service encounter. The availability of BOPS and other no-contact delivery modes have played an important role for physical stores during the COVID-19 pandemic.

However, the pick-up service should be designed to allow the retailer to maintain cross-selling opportunities and provide the desired quality at the same time. For instance, the pick-up counter or lockers can be located near the stock of on-sale items, or best-selling items can be displayed in the pick-up waiting area to increase the chance of additional purchases. While delivery-to-car services discourage customers from browsing the physical store, retailers may implement some triggers of additional purchases through marketing tools such as locating kiosk machines in the parking lot.

\subsection{Limitations and future study directions}

The current study has several limitations that can be addressed in future studies. First, researchers may extend BOPS-PUQUAL by applying the distinction between different pick-up methods. Retailers are currently adopting various service forms of BOPS pick-up in addition to the in-store counter pick-up served by employees, such as curbside pick-ups, pick-up lockers, delivery-to-car service, and pick-up towers. Service quality perceptions of these new pick-up formats might differ from that of the classic in-store counter pick-up addressed in our study. 
Second, future studies can validate our proposed scale using different sources of data. While prior studies have demonstrated the sufficient quality of data collected by Mturk (Buhrmester et al. 2011; Lee et al. 2018), a future replication study with field data could improve the external validity of the BOPS-PU-QUAL scale.

Third, our study results show that the correlation between service effectiveness and problem-handling is quite high $(r=.80)$. Although the discriminant validity standard is satisfied (i.e., the square root of AVE of the constructs are greater than the inter-construct correlations), the high correlation should be noted. However, the two distinct dimensions in our scale agree with prior studies on retail service quality and multichannel service quality (Dabholkar et al. 1996; Cassab and MacLachlan 2009). Future studies with different datasets can further validate the distinctiveness of the two dimensions.

Fourth, the effect of each dimension of our scale may vary by the circumstances of the purchase. For example, customers may have different expectations towards the pick-up service depending on the retailer. Also, they may be less sensitive to service effectiveness if they chose BOPS because of the shipping fee, or more sensitive if the price of the item is high. We tested the effect of retailer type and found no significant influence on both perceived service quality and satisfaction with BOPS in our regression analysis $(b=-.04, S E=.07, p>.05$ for perceived service quality; $b=.03, S E=.07, p>.05$ for satisfaction with BOPS). However, testing the effects of variables such as the shipping fee and order price will foster a deeper understanding of the relative importance of BOPS-PUQUAL dimensions.

Availability of data and material Data collected and analyzed during the current study are available from the first author on reasonable request.

Authors' contributions All authors contributed to all phases of the study development, from study conception and design to writing and revision. All authors read and approved the final manuscript.

Funding information The research was not funded by external entities.

\section{Compliance with ethical standards}

Conflict of interest The authors have no conflicts of interests to disclose.

Code availability Not applicable.

\section{References}

Acquila-Natale E, Iglesias-Pradas S (2020) How to measure quality in multi-channel retailing and not die trying. J Bus Res 109:38-48. https://doi.org/10.1016/j.jbusres.2019.10.041

Adobe Analytics (2020) Adobe digital economy index. https://www. adobe.com/experience-cloud/digital-insights/digital-economyindex.html. Accessed 23 July 2020
Ajzen I (1985) From intentions to actions: a theory of planned behavior. In: Kuhl J, Beckman J (eds) Action control: from cognition to behavior. Springer, Berlin, pp 11-39

Ajzen I, Madden TJ (1986) Prediction of goal-directed behavior: attitudes, intentions, and perceived behavioral control. J Exp Soc Psychol 22:453-474. https://doi.org/10.1016/0022-1031(86) 90045-4

Akturk MS, Ketzenberg M, Heim GR (2018) Assessing impacts of introducing ship-to-store service on sales and returns in omnichannel retailing: a data analytics study. J Oper Manag 61:15-45. https:// doi.org/10.1016/j.jom.2018.06.004

Arnold MJ, Reynolds KE (2003) Hedonic shopping motivations. J Retail 79:77-95. https://doi.org/10.1016/S0022-4359(03)00007-1

Babakus E, Boller GW (1992) An empirical assessment of the SERVQUAL scale. J Bus Res 24:253-268. https://doi.org/10. 1016/0148-2963(92)90022-4

Babakus E, Mangold WG (1992) Adapting the SERVQUAL scale to hospital services: an empirical investigation. Health Serv Res 26: 767-786. https://www.ncbi.nlm.nih.gov/pmc/articles/ PMC1069855/

Bagozzi RP, Yi Y (1988) On the evaluation of structural equation models. J Acad Mark Sci 16:74-94. https://doi.org/10.1007/BF02723327

Baker DA, Crompton JL (2000) Quality, satisfaction and behavioral intentions. Ann Tour Res 27:785-804. https://doi.org/10.1016/S01607383(99)00108-5

Barnes SJ, Vidgen RT (2002) An integrative approach to the assessment of e-commerce quality. J Electron Commer Res 3:114-127. http:// www.jecr.org/node/271

Barr S (2018) Don't want to wait or pay for shipping? Just click and collect. Forbes. https://www.forbes.com/sites/stevenbarr/2018/01/ 30/dont-want-to-wait-or-pay-for-shipping-just-click-and-collect/. Accessed 21 December 2019

Bell and Howell (2017) Click and collect retail consumer preference study. https://bellhowell.net/cms/wp-content/uploads/2018/05/Belland-Howell-Click-and-Collect-Retail-Consumer-Preference-Study. pdf. Accessed 21 December 2019

Bell DR, Gallino S, Moreno A (2018) The store is dead-long live the store. MIT Sloan Manag Rev 59:59-66. https://sloanreview.mit. edu/article/the-store-is-dead-long-live-the-store/

Berman B, Thelen S (2004) A guide to developing and managing a wellintegrated multi-channel retail strategy. Int J Retail Distrib Manag 32:147-156. https://doi.org/10.1108/09590550410524939

Bitner MJ, Booms BH, Tetreault MS (1990) The service encounter: diagnosing favorable and unfavorable incidents. J Mark 54:71-84. https://doi.org/10.1177/002224299005400105

Brady MK, Cronin JJ (2001) Some new thoughts on conceptualizing perceived service quality: a hierarchical approach. J Mark 65:34 49. https://doi.org/10.1509/jmkg.65.3.34.18334

Buhrmester M, Kwang T, Gosling SD (2011) Amazon's mechanical Turk: a new source of inexpensive, yet high-quality data? Perspect Psychol Sci 6:3-5. https://doi.org/10.1037/14805-009

Bustamante JC, Rubio N (2017) Measuring customer experience in physical retail environments. J Serv Manag 28:884-913. https://doi.org/ 10.1108/JOSM-06-2016-0142

Cambra-Fierro J, Melero-Polo I, Patrício L, Sese FJ (2020) Channel habits and the development of successful customer-firm relationships in services. J Serv Res. https://doi.org/10.1177/ 1094670520916791

Caruana A (2002) Service loyalty: the effects of service quality and the mediating role of customer satisfaction. Eur J Mark 36:811-828. https://oi.org/10.1108/03090560210430818

Cassab H, MacLachlan DL (2009) A consumer-based view of multichannel service. J Serv Manag 20:52-75. https://doi.org/10.1108/ 09564230910936850 
Chatterjee P (2010) Causes and consequences of 'order online pick up instore' shopping behavior. Int Rev Retail Distrib Consum Res 20: 431-448. https://doi.org/10.1080/09593969.2010.504009

Cheung GW, Lau RS (2008) Testing mediation and suppression effects of latent variables: bootstrapping with structural equation models. Organ Res Methods 11:296-325. https://doi.org/10.1177/ 1094428107300343

Churchill GA (1979) A paradigm for developing better measures of marketing constructs. J Mark Res 16:64-73. https://doi.org/10.1177/ 002224377901600110

Cronin JJ, Taylor SA (1992) Measuring service quality: a reexamination and extension. J Mark 56:55-68. https://doi.org/10.1177/ 002224299205600304

Cronin JJ, Brady MK, Hult GTM (2000) Assessing the effects of quality, value, and customer satisfaction on consumer behavioral intentions in service environments. J Retail 76:193-218. https://doi.org/10. 1016/S0022-4359(00)00028-2

Dabholkar PA, Bagozzi RP (2002) An attitudinal model of technologybased self-service: moderating effects of consumer traits and situational factors. J Acad Mark Sci 30:184-201. https://doi.org/10.1177/ 0092070302303001

Dabholkar PA, Thorpe DI, Rentz JO (1996) A measure of service quality for retail stores: scale development and validation. J Acad Mark Sci 24:3-16. https://doi.org/10.1007/BF02893933

Davis FD (1989) Perceived usefulness, perceived ease of use, and user acceptance of information technology. MIS Q 13:319-340. https:// doi.org/10.2307/249008

Euromonitor International (2018) Retailing in the US. https://www. euromonitor.com. Accessed 21 December 2019

Field JM, Xue M, Hitt LM (2012) Learning by customers as co-producers in financial services: an empirical study of the effects of learning channels and customer characteristics. Oper Manag Res 5:43-56. https://doi.org/10.1007/s12063-012-0064-Z

Flanagan JC (1954) The critical incident technique. Psychol Bull 51:327358. https://doi.org/10.1037/h0061470

Fornell C, Larcker DF (1981) Evaluating structural equation models with unobservable variables and measurement error. J Mark Res 18:3950. https://doi.org/10.1177/002224378101800104

Forrester (2014) Customer desires vs retailer capabilities: minding the omni-channel commerce gap. https://www.accenture.com/us-en/ r/media/accenture/conversion-assets/dotcom/documents/global/ pdf/technology_7/accenture-customer-desires-vs-retailercapabilities.pdf. Accessed 21 December 2019

Forsythe SM, Shi B (2003) Consumer patronage and risk perceptions in internet shopping. J Bus Res 56:867-875. https://doi.org/10.1016/ S0148-2963(01)00273-9

Gallino S, Moreno A (2014) Integration of online and offline channels in retail: the impact of sharing reliable inventory availability information. Manag Sci 60:1434-1451. https://doi.org/10.1287/mnsc.2014. 1951

Gao F, Su X (2016) Omnichannel retail operations with buy-online-andpick-up-in-store. Manag Sci 63:2478-2492. https://doi.org/10.1287/ mnsc.2016.2473

Gollwitzer PM (1993) Goal achievement: the role of intentions. Eur Rev Soc Psychol 4:141-185. https://doi.org/10.1080/14792779343000059

Graham JW (2009) Missing data analysis: making it work in the real world. Annu Rev Psychol 60:549-576. https://doi.org/10.1146/ annurev.psych.58.110405.085530

Gremler DD (2004) The critical incident technique in service research. J Serv Res 7:65-89. https://doi.org/10.1177/1094670504266138

Hair JF, Anderson RE, Tatham RL, Black WC (1998) Multivariate data analysis. Prentice Hall, Upper Saddle River

Harris KE, Grewal D, Mohr LA, Bernhardt KL (2006) Consumer responses to service recovery strategies: the moderating role of online versus offline environment. J Bus Res 59:425-431. https://doi.org/ 10.1016/j.jbusres.2005.10.005
Herhausen D, Binder J, Schoegel M, Herrmann A (2015) Integrating bricks with clicks: retailer-level and channel-level outcomes of online-offline channel integration. J Retail 91:309-325. https:// doi.org/10.1016/j.jretai.2014.12.009

Hinkin TR (1998) A brief tutorial on the development of measures for use in survey questionnaires. Organ Res Methods 1:104-121. https:// doi.org/10.1177/109442819800100106

Hoffman KD, Kelley SW, Rotalsky HM (1995) Tracking service failures and employee recovery efforts. J Serv Mark 9:49-61. https://doi.org/ $10.1108 / 08876049510086017$

Hsu T, Wingfield N (2018) Walmart expands online grocery delivery to 100 cities. The New York Times. https:/www.nytimes.com/2018/ 03/14/business/dealbook/walmart-online-delivery-groceries.html. Accessed 21 December 2019

Jara M, Vyt D, Mevel O, Morvan T, Morvan N (2018) Measuring customers benefits of click and collect. J Serv Mark 32:430-442. https://doi.org/10.1108/JSM-05-2017-0158

JDA (2017) The 2017 consumer survey. https://jda.com/-/media/jda/ knowledge-center/thought-leadership/2017-jda-consumer-surveyexecutive-summary.ashx. Accessed 21 December 2019

Kaiser HF (1960) The application of electronic computers to factor analysis. Educ Psychol Meas 20:141-151. https://doi.org/10.1177/ 001316446002000116

Kim J, Muller CW (1978) Introduction to factor analysis: what it is and how to do it. Sage, Beverly Hills

Kim E, Park M-C, Lee J (2017) Determinants of the intention to use BuyOnline, Pickup In-Store (BOPS): the moderating effects of situational factors and product type. Telemat Inform 34:1721-1735. https:// doi.org/10.1016/j.tele.2017.08.006

Konuş U, Verhoef PC, Neslin SA (2008) Multichannel shopper segments and their covariates. J Retail 84:398-413. https://doi.org/10.1016/j. jretai.2008.09.002

Krippendorff K (1980) Content analysis: an introduction to its methodology, 3rd edn. Sage, Beverly Hills

Kushwaha T, Shankar V (2013) Are multichannel customers really more valuable? The moderating role of product category characteristics. J Mark 77:67-85. https://doi.org/10.1509/jm.11.0297

Lee YS, Seo YW, Siemsen E (2018) Running behavioral operations experiments using Amazon's mechanical Turk. Prod Oper Manag 27:973-989. https://doi.org/10.1111/poms.12841

Levy M, Weitz BA, Grewal D (2014) Retailing management, 9th edn. McGraw-Hill, New York

Lockwood A (1994) Using service incidents to identify quality improvement points. Int J Contemp Hosp Manag 6:75-80. https://doi.org/ $10.1108 / 09596119410052170$

Loiacono ET, Watson RT, Goodhue DL (2007) WebQual: an instrument for consumer evaluation of web sites. Int J Electron Commer 11:5187. https://doi.org/10.2753/JEC1086-4415110302

MacCallum RC, Browne MW, Sugawara HM (1996) Power analysis and determination of sample size for covariance structure modeling. Psychol Methods 1:130-149. https://doi.org/10.1037/1082-989X. 1.2 .130

MacKinnon DP, Lockwood CM, Williams J (2004) Confidence limits for the indirect effect: distribution of the product and resampling methods. Multivar Behav Res 39:99-128. https://doi.org/10.1207/ s15327906mbr3901_4

McCabe DB, Rosenbaum MS, Yurchisin J (2007) Perceived service quality and shopping motivations: a dynamic relationship. Serv Mark Q 29:1-21. https://doi.org/10.1300/J396v29n01_01

Mentzer JT, Flint DJ, Hult GTM (2001) Logistics service quality as a segment-customized process. J Mark 65:82-104. https://doi.org/10. 1509/jmkg.65.4.82.18390

Meuter ML, Ostrom AL, Roundtree RI, Bitner MJ (2000) Self-service technologies: understanding customer satisfaction with technologybased service encounters. J Mark 64:50-64. https://doi.org/10.1509/ jmkg.64.3.50.18024 
Murfield M, Boone CA, Rutner P, Thomas R (2017) Investigating logistics service quality in omni-channel retailing. Int J Phys Distrib Logist Manag 47:263-296. https://doi.org/10.1108/IJPDLM-062016-0161

Neslin SA, Grewal D, Leghorn R, Shankar V, Teerling ML, Thomas JS, Verhoef PC (2006) Challenges and opportunities in multichannel customer management. J Serv Res 9:95-112. https://doi.org/10. $1177 / 1094670506293559$

Neter J, Kutner MH, Nachtsheim CJ, Wasserman W (1996) Applied linear statistical models, 4th edn. McGraw-Hill, New York

Nunnally J (1978) Psychometric methods. McGraw-Hill, New York

Olorunniwo F, Hsu MK, Udo GJ (2006) Service quality, customer satisfaction, and behavioral intentions in the service factory. J Serv Mark 20:59-72. https://doi.org/10.1108/08876040610646581

Parasuraman A, Zeithaml VA, Berry LL (1985) A conceptual model of service quality and its implications for future research. J Mark 49: 41-50. https://doi.org/10.1177/002224298504900403

Parasuraman A, Zeithaml VA, Berry LL (1988) SERVQUAL: a multiple-item scale for measuring consumer perceptions of service quality. J Retail 64:12-40. http://www.journals.elsevier.com/ journal-of-retailing/

Parasuraman A, Zeithaml VA, Malhotra A (2005) ES-QUAL: a multipleitem scale for assessing electronic service quality. J Serv Res 7:213233. https://doi.org/10.1177/1094670504271156

Rosenmayer A, McQuilken L, Robertson N, Ogden S (2018) Omnichannel service failures and recoveries: refined typologies using Facebook complaints. J Serv Mark 32:269-285. https://doi.org/10. 1108/JSM-04-2017-0117

Roth AV, Schroeder RG, Kristal MM, Huang X (2008) Handbook of metrics for research in operations management: multi-item measurement scales and objective items. Sage, Thousand Oaks

Schmaus B, Maekelburger B, Felsmann D (2017) The 2017 global omnichannel retail index: omnichannel on the march. PWC. https://www.strategyand.pwc.com/gx/en/insights/2017/2017global-omnichannel-retail-index.html. Accessed 21 December 2019

Schröder H, Zaharia S (2008) Linking multi-channel customer behavior with shopping motives: an empirical investigation of a German retailer. J Retail Consum Serv 15:452-468. https://doi.org/10.1016/j. jretconser.2008.01.001

Song P, Wang Q, Liu H, Li Q (2020) The value of buy-online-and-pickup-in-store in omni-channel: evidence from customer usage data. Prod Oper Manag 29:995-1010. https://doi.org/10.1111/poms. 13146

Sopadjieva E, Dholakia U, Benjamin B (2017) A study of 46,000 shoppers shows that omnichannel retailing works. Harv Bus Rev 3:12. https://hbsp.harvard.edu/

Sousa R, Voss CA (2006) Service quality in multichannel services employing virtual channels. J Serv Res 8:356-371. https://doi.org/ $10.1177 / 1094670506286324$

Swaid SI, Wigand RT (2012) The effect of perceived site-to-store service quality on perceived value and loyalty intentions in multichannel retailing. Int J Manag 29:301-313
Szymanski DM, Hise RT (2000) E-satisfaction: an initial examination. J Retail 76:309-322. https://doi.org/10.1016/S0022-4359(00)00035$\mathrm{X}$

Taylor SA, Baker TL (1994) An assessment of the relationship between service quality and customer satisfaction. J Retail 70:163-178. https://doi.org/10.1016/0022-4359(94)90013-2

Venkatesan R, Kumar V, Ravishanker N (2007) Multichannel shopping: causes and consequences. J Mark 71:114-132. https://doi.org/10. 1509/jmkg.71.2.114

Venkatesh V, Davis FD (2000) A theoretical extension of the technology acceptance model: four longitudinal field studies. Manag Sci 46: 186-204. https://doi.org/10.1287/mnsc.46.2.186.11926

Verhoef PC, Neslin SA, Vroomen B (2007) Multichannel customer management: understanding the research-shopper phenomenon. Int $\mathrm{J}$ Res Mark 24:129-148. https://doi.org/10.1016/j.ijresmar.2006.11. 002

Verhoef PC, Kannan PK, Inman JJ (2015) From multi-channel retailing to omni-channel retailing: introduction to the special issue on multichannel retailing. J Retail 91:174-181. https://doi.org/10.1016/j. jretai.2015.02.005

Weaver B, Maxwell H (2014) Exploratory factor analysis and reliability analysis with missing data: a simple method for SPSS users. Quant Method Psychol 10:143-152. https://doi.org/10.20982/tqmp.10.2. p143

Wu J-F, Chang YP (2016) Multichannel integration quality, online perceived value and online purchase intention: a perspective of landbased retailers. Internet Res 26:1228-1248. https://doi.org/10.1108/ IntR-04-2014-0111

Xue M, Harker PT (2002) Customer efficiency: concept and its impact on e-business management. J Serv Res 4:253-267. https://doi.org/10. $1177 / 1094670502004004003$

Xue M, Hitt LM, Harker PT (2007) Customer efficiency, channel usage, and firm performance in retail banking. Manuf Serv Oper Manag 9: 535-558. https://doi.org/10.1287/msom.1060.0135

Zeithaml VA, Berry LL, Parasuraman A (1996) The behavioral consequences of service quality. J Mark 60:31-46. https://doi.org/10. 1177/002224299606000203

Zhang T, Lu C, Torres E, Chen P-J (2018) Engaging customers in value co-creation or co-destruction online. J Serv Mark 32:57-69. https:// doi.org/10.1108/JSM-01-2017-0027

Zhang M, He X, Qin F, Fu W, He Z (2019) Service quality measurement for omni-channel retail: scale development and validation. Total Qual Manag Bus Excell 30:S210-S226. https://doi.org/10.1080/ 14783363.2019.1665846

Zwick WR, Velicer WF (1986) Comparison of five rules for determining the number of components to retain. Psychol Bull 99:432-442. https://doi.org/10.1037/0033-2909.99.3.432

Publisher's note Springer Nature remains neutral with regard to jurisdictional claims in published maps and institutional affiliations. 